\title{
Subsociality and Female Reproductive Success in a Mycophagous Thrips: An Observational and Experimental Analysis
}

\author{
Bernard J. Crespi ${ }^{1,2}$ \\ Accepted October 17, 1988; revised February 6, 1989
}

Oviparous females of the haplodiploid, facultatively viviparous thrips Elaphrothrips tuberculatus (Thysanoptera: Phlaeothripidae) guard their eggs against female conspecifics and other egg predators. The intensity of maternal defense increases with clutch size. Field and laboratory observations indicate that cannibalism by females is an important selective pressure favoring maternal care. Experimental removals of guarding females showed that egg guarding substantially increases egg survivorship and that the survivorship of undefended eggs is higher in the absence of nonguarding female conspecifics than in their presence. The fecundity of viviparous females increases with the number of eggs cannibalized. The reproductive success of oviparous females increases with body size and local food density and decreases with local density of breeding females. Social behavior may not have advanced beyond maternal care in Elaphrothrips tuberculatus because, relative to Hymenoptera, capabilities for helping relatives are few or nonexistent, and the causes of variation in female reproductive success are not influenced easily by cooperation among females.

KEY WORDS: thrips; subsociality; cannibalism; reproductive success.

\section{INTRODUCTION}

Adults of many insect species defend or provision their young (reviewed by Eickwort, 1981; Tallamy and Wood, 1986). Parental care is generally considered an adaptation to harsh conditions which would substantially decrease the

\footnotetext{
${ }^{1}$ Museum of Zoology and Department of Biology, University of Michigan, Ann Arbor, Michigan 48109-1079.

${ }^{2}$ Present address: Department of Zoology, South Parks Road, Oxford University, Oxford OX1 3PS, U.K.
} 
survivorship of offspring were they unprotected. However, the selective pressures responsible for the origin and maintenance of parental behavior in its various forms are not thoroughly understood. Detecting and measuring selection on this set of traits is important for studying the evolution of social behavior, because the causes of simple parental care are at one end of a continuum of phylogenetic, ecological, and genetic factors leading to eusociality, and the specification of these factors and their relative contributions to behavior form the basis for analyzing social evolution. For example, parasites and predators have been considered as the primary selective agents for maternal care and eusociality (e.g., Lin, 1964; Michener, 1974, pp. 245-248; Litte, 1977; WestEberhard, 1978; Edgerly, 1987). However, critical evaluation of this hypothesis requires comparison of population or species that differ in both social structure and the prevalence of this agent of selection and experimental manipulation of predator or parasite pressure to see what their direct effects on sociality might be. Similarly, the genetic asymmetries of hymenopteran haplodiploidy are sometimes regarded as causal in the evolution of sociality, because incipient female helpers are more closely related to full sisters than to their own offspring (Hamilton, 1964, 1972). However, the Hymenoptera also exhibit a constellation of ecological and behavioral traits that may favor helping behavior, such as a high prevalence of simple parental care, nesting in protected locations, ability to build and improve nests, and the spectacular opportunities for heroism afforded by the sting (Hamilton, 1972; Eickwort, 1981; Andersson, 1984; Alexander et al., 1989).

Analysis of parental care and sociality, using either comparative or experimental methods, requires partitioning genetic, phylogenetic, ecological, and demographic effects on behavior. The Thysanoptera offer unique opportunities to study the contributions of genetic asymmetries and other variables to social behavior, because this insect order is haplodiploid, exhibits a wide variety of life histories, and shows a wide range of social interactions. Egg defense, generally by adult females, has been reported in thrips by Bagnall (1915), Ramakrishna Ayyar (1928), Hean (1943), Mani and Rao (1950), Ananthakrishnan (1984), and Kiester and Strates (1984), and observations by Haga (1980) indicate that in Bactrothrips brevitubus (Takahashi) males may also engage in parental behavior. Moreover, Crespi (1986a, 1987, 1988a) reported that in two species of Hoplothrips female oviposit communally, and Kiester and Strates (1984) described the behavior of a species of Anactinothrips that exhibits coordinated group foraging behavior. These data suggest that the order Thysanoptera comprises species with complex social organization, such that they may provide novel insights into the evolution of sociality.

The purpose of this paper is to analyze the selective pressures associated with maternal care and female reproductive success in oviparous females of Elaphrothrips tuberculatus (Hood), a bivoltine, facultatively viviparous thrips. 
Data from observations, collections, and experiments indicate that (1) the primary selective agent for maternal behavior in this species is egg cannibalism by adult females, and (2) female reproductive success is influenced by body size, local food density, and the local density of adult females.

\section{MATERIALS AND METHODS}

\section{E. tuberculatus Life History}

E. tuberculatus, a thrips about $5 \mathrm{~mm}$ long, inhabits clusters of hanging dead oak leaves (Quercus velutina and $Q$. rubra in Michigan) and feeds on spores of the ascomycete fungus Pseudomassaria polystigma (Crespi, 1986b, 1987). Its range apparently extends throughout eastern North America (Stannard, 1968; Crespi, personal observation). In southern Michigan, both sexes overwinter as adults in leaf litter, emerge in mid-April to mid-May, and undergo two partially overlapping generations per year. Adults disperse by flight during early spring and at the end of the first (spring) generation.

Female E. tuberculatus produce male offspring by viviparity and female offspring by oviparity (Crespi, 1987, 1988b, 1989). Observations of marked adults in the field and breeding experiments indicate that during the 1-month spring breeding period, individual females normally remain either oviparous or viviparous (Crespi, 1986b, 1987). However, during the 2-month summer breeding period, some females switch reproductive mode (Crespi, 1989). Males fight each other with their enlarged, armed forelegs in defense of individual oviparous females (Crespi, 1986b, 1987), large males win fights (Crespi, 1986b, 1987), and smaller males often adopt an alternative mating tactic of attempting to "sneak" matings (Crespi, 1988c).

\section{Field Observations}

The observations of female guarding and cannibalism described here were conducted between 23 May and 11 June 1984 on 22 females and 19 males inhabiting a cluster of 37 black oak leaves (Crespi, 1986b). Most of the males and females were marked individually on their thoraces with colored dots of Testor's enamel paint. Since these were the first field observations of $E$. tuberculatus, data on female behavior were recorded ad libitum.

Oviposition rates and durations were measured by putting several dozen females on leaf clusters in the field and recording, for oviparous females, (1) date of initiation and termination of egg-laying, (2) clutch size, and (3) female size [correlations between several of these variables are given by Crespi (1987)]. For viviparous females, the rate and duration of producing first-instar larvae were measured by putting partially gravid field-collected females individually 
in $50 \times 9$-mm petri dishes containing several pieces of dampened oak leaf and every second day counting the number of larvae produced. Near the end of the breeding period, the females were dissected and the number of larvae remaining in their abdomens was recorded. These reproductive parameters of viviparous females were measured to compare them to those of oviparous females.

\section{Field Collections}

During the spring breeding periods (April-June) of 1985, 1986, and 1987 leaf clusters containing $E$. tuberculatus were collected in oak-hickory woodlands in Washtenaw and Livingston counties, Michigan (Crespi, 1987). To analyze the causes of variation in oviparous female fecundity and the proportion of eggs that were collapsed, I measured, for each leaf cluster, the number of males and females, female breeding status (viviparous, oviparous and guarding eggs, or oviparous and not guarding eggs), and number of leaves. In the spring of 1987 , the density of fungal fruiting bodies was measured by using an ocular micrometer to sum the lengths of the intersections of a measured transect with the fruiting bodies, which form round black dots on the back of the leaves (Crespi, 1988b). For each oviparous female that had completed her clutch of eggs, I recorded three variables: (1) female size (fore-femora length, mm), (2) clutch size (number of eggs laid), and (3) number of eggs that were collapsed. Some data were collected in only 1 or 2 of the 3 years.

To analyze the causes of variation in offspring survivorship to the pupal stage and offspring adult size, the pupal offspring of spring adults were collected in the field in late June through mid-July of 1984 and 1985 . These offspring were collected by choosing leaf clusters on which at least $80 \%$ of the thrips were either pupae or large second-instar larvae (the last instar before pupation), and isolating these clusters in sealed plastic bags until the thrips had molted to adulthood 9-11 days later. These leaf clusters contained the female offspring of from 1 to 21 oviparous females and the male offspring of viviparous females. For each leaf cluster, I measured four variables: (1) offspring sex, (2) total number of egg masses and number of hatched and undeveloped eggs in each, (3) offspring size, measured as fore-femora length (described above), and (4) density of fungal fruiting bodies on the leaves (measured as described above, only in 1984). The survivorship of female offspring to the pupal stage was estimated by dividing the number of female adults by the total number of eggs.

\section{Experiments}

Five experiments were conducted to analyze the selective pressures associated with female egg-guarding and female fecundity.

1. Variation in the Intensity of Maternal Defense over the Oviposition Period. This experiment tested the hypothesis that the intensity of maternal 
defense increases with the reproductive value of the clutch. The intensity of maternal defense was evaluated by taking guarding females collected in the field within the previous few hours and touching them as gently as possible on the side of the posterior part of their abdomens with the tips of fine forceps at intervals of $5 \mathrm{~s}$ until they abandoned their clutches of eggs. The number of prods until abandonment was used as an estimate of the intensity of maternal defense. The number of prods was related to three measures of reproductive value of the clutch: (1) the total number of collapsed and intact eggs guarded by a female, (2) the number of intact eggs, and (3) the proportion of the expected total number of eggs that a female had laid at that time. Expected total clutch size was estimated by measuring the fore-femora length of the females and predicting the total clutch size from the regression of completed clutch size on female size (computed using 1986 field data). The proportion of her expected total clutch that a female had laid at the time of the experiment was computed by dividing a female's observed clutch size by her predicted total clutch size.

2. Sex Differences in Egg Cannibalism. This experiment was conducted to determine whether females and males differ in the presence or extent of egg cannibalism. Ten males and ten females were put individually into $50 \times 9-\mathrm{mm}$ petri dishes, each containing one unguarded egg mass, and the number of eggs collapsed and intact were counted after 24 and $48 \mathrm{~h}$.

3. Removal of Guarding Females in the Field. This experiment tested the hypothesis that female guarding increases egg survivorship in the field. On 7 May 1986, every second guarding female encountered was removed from her egg mass, for a total of 30 females removed from 16 leaf clusters. On 14 May, these leaf clusters were collected, and clutch sizes and numbers of eggs intact and collapsed were measured.

4. Removal of Guarding Females, Controlling for Presence or Absence of Nonguarding Females. This experiment tested the hypothesis that the presence of females that were not guarding eggs affects the egg survivorship of eggs of guarding females or the survivorship of eggs on egg masses whose guarding female has been removed. Eleven clusters of three to five leaves were set up in the field on 10 May: six contained one guarding female, two or three unguarded egg masses, and eight females which were not guarding eggs, and five contained one guarding female, two or three unguarded egg masses, and no additional females. The unguarded egg masses used had no or very few eggs collapsed initially and had similar numbers of eggs in the two treatment groups. On 17 May all of the egg masses were collected, and the numbers of intact and collapsed eggs were counted.

5. The Effects of Egg Cannibalism on Female Fecundity. This experiment was designed to test the hypothesis that cannibalism increases female fecundity. On 21 May 1988, 60 field-collected females were put individually into nylon bags containing two large leaves. To standardize feeding conditions, all of the 
leaves were from the same large leaf cluster. Unguarded egg masses on approximately $3 \times 8-\mathrm{cm}$ pieces of leaf were added to half of these leaf clusters, by clipping the piece of leaf to one of the large leaves. These clusters represent the experimental treatment, and the control comprised females in bags containing similar small pieces of leaf with no egg masses. On 26 May, a second egg mass was added to the experimental treatments, and on 12 June the egg masses were removed and the numbers of collapsed and intact eggs were counted. Because some of the females in the experimental treatment did not cannibalize any eggs, these data were analyzed with respect to number of eggs cannibalized. Oviparous female fecundity was measured as the number of eggs laid, and viviparous female fecundity was measured as the number of first-instar and secondinstar larvae found on the leaves.

\section{RESULTS}

\section{Oviposition and Egg-Guarding}

Females oviposit and guard their eggs in sheltered locations on the leaf clusters, such as in curled areas of leaf or between leaves juxtaposed closely and in parallel. The average duration from initiation to completion of egg-laying was $14.9 \pm 3.3$ days (range, $10-21 ; N=24$ ). Large oviparous females laid eggs at a higher rate than did smaller ones (product-moment correlation, $r=$ $0.48, N=24, P<0.05)$ rather than over longer periods of time $(r=-0.04$, $N=24, P>0.50$ ) (Crespi, 1987). Similarly, large viviparous females produced larvae at a higher rate than smaller ones $(r=0.64, N=53, P<0.001)$ (breeding duration was not measured for viviparous females).

Guarding females stand over their egg masses and curl the end of their abdomens toward approaching threats. If certain threats, such as the tips of fine forceps, approach within a few millimeters of a guarding female, the female produces a drop of brown fluid from the end of her abdomen, which is held in the anal setae. This drop, which contains the toxic chemical juglone (Blum, Howard, and Crespi, unpublished), is deposited on the approaching threat with a quick movement of the abdomen. Experiments involving plugging the end of the abdomen have shown that a female's use of this chemical defense repels salticid spiders which otherwise capture and eat them (Blum, Howard, and Crespi, unpublished). However, guarding females have not been observed to use this defense against cannibalistic females (described below) or against a parasitoid wasp (Thripoctenus sp.) (Hymenoptera: Eulophidae) which oviposits into first-instar larvae on or near a guarded egg mass.

Females leave their egg masses and feed on fungal spores on the back side of the leaves when the leaves are wet with rain or dew. During these feeding periods, which usually last for several but less than $30 \mathrm{~min}$, the eggs are unde- 
fended. Twelve of 15 observed cannibalism attempts (described below), and six of seven successful cannibalism episodes, occurred when the leaves were wet, and three of these six successful cannibalism episodes occurred when the guarding females were away feeding for the entire period.

The intensity of maternal defense, measured as the number of prods with forceps until egg mass abandonment, was positively correlated with the total number of eggs laid (product-moment correlation, $r=0.48, N=37, P<$ $0.01)$ (Fig. 1), total number of eggs intact $(r=0.52, N=37, P<0.01)$, and proportion of a female's predicted total clutch that she had laid when tested $(r$ $=0.50, N=37, P<0.01$ ). Because these three correlations were nearly identical, and the three measures of reproductive value of the clutch were highly correlated $(r=0.92-0.98)$, it was not possible with these data to determine which variable most directly affects the intensity of maternal defense.

After the eggs have begun hatching, females usually remain to one side of egg masses. A guarding female defends against parasitoid wasps by rushing toward the wasp and grasping at it with the forelegs. Usually, wasps run away rapidly and avoid approaching females. However, on one occasion, a female caught and held a wasp with her forelegs for several seconds, after which the thrips and wasp separated and continued behaving as before. Females usually guard their eggs until all have hatched, after which they sometimes remain in

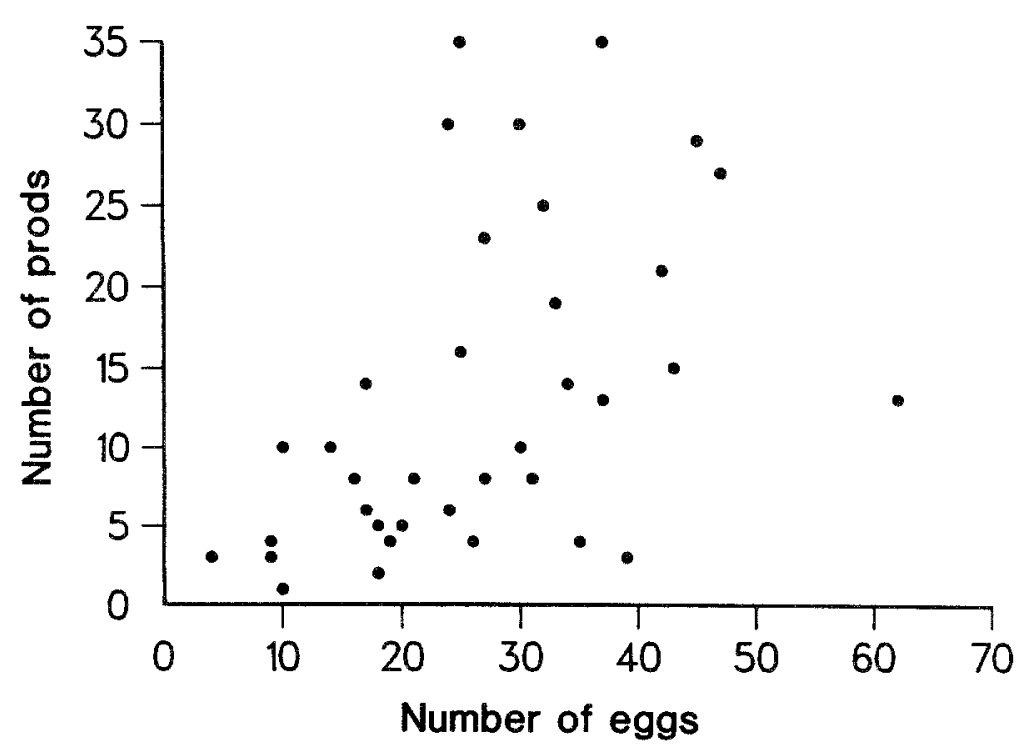

Fig. 1. The relationship between the number of prods with forceps until clutch abandonment (a measure of willingness to invest in the clutch) and clutch size (a measure of the value of the clutch) in the subsocial thrips Elaphrothrips tuberculatus. 
the vicinity of the larvae and egg mass but apparently do not engage in defensive behavior.

\section{Cannibalism and Experimental Removal of Guarding Females}

Egg cannibalism was observed in the field when a nonguarding female approached an egg mass, stood with her head over the eggs for periods varying from a few seconds to a few minutes, and tilted her head back in the position used when feeding. In the laboratory, cannibalizing females exhibited an identical position and behavior, and observations under a dissecting microscope showed that (1) females insert their mouthparts into the eggs and remain in this position for several minutes, (2) eggs that have been fed upon collapse, and (3) these eggs resemble the collapsed eggs found in the field.

In the field, cannibalism was observed clearly seven times, and apparent attempted cannibalism was observed eight times. Of the seven cases of successful cannibalism, the guarding female was away from her eggs for the entire period in three cases, but in four cases the guarding female returned and the two females engaged in agonistic interactions that involved the guarding female rushing at the cannibalizing female, attempting to grasp her with the forelegs, and walking forward when in contact. Of the eight cases of unsuccessful apparent cannibalism, three were interrupted by the approach of the guarding female as the intruding female slowly neared the eggs, and in the other five cases the two females engaged in agonistic interactions as described above. Most (eight of nine) of these agonistic interactions were only a few seconds long and ended with the retreat of the intruding female. However, in one case where the intruder female was much larger than the guarding female, this larger female drove the smaller one away and apparently cannibalized her entire egg mass.

Laboratory experiments involving isolation of either one male or one female in a petri dish with an undefended egg mass for $48 \mathrm{~h}$ showed that only females cannibalize eggs. The undefended egg masses initially contained $11.0 \pm 5.0$ eggs (for the 10 females) and $11.7 \pm 5.9$ eggs (for the 10 males) $(t=0.29, P$ $>0.50$ ), and the initial proportion of eggs intact was $0.86 \pm 0.20$ (for females) and $0.88 \pm 0.13$ (for males) $(t=0.3, P>0.50$ ). For females, the proportion of eggs intact was $0.28 \pm 0.25$ after $24 \mathrm{~h}$ and $0.17 \pm 0.24$ after $48 \mathrm{~h}$. No males cannibalized eggs. All of the females cannibalized part of an egg mass, and 7 of 10 cannibalized all or all but one of the eggs.

Field removals of every second guarding female showed that experimental termination of egg guarding greatly decreases egg survivorship. The proportion of eggs that were intact 1 week after female removal was $0.89 \pm 0.14(N=$ $20)$ for egg masses with guarding females and $0.44 \pm 0.44(N=22)$ for undefended egg masses $(t=4.4, P<0.001)$. On 7 of 22 of the undefended egg masses all of the eggs were collapsed, on 5 of them some eggs were collapsed, 
on 6 of them all eggs were present and intact, and on 4 egg masses many of the eggs were gone and the remaining ones were entirely or partially collapsed $(N=3)$ or all intact $(N=1)$.

Experimental removal of guarding females, controlling for the presence of nonguarding females on the leaf clusters, showed that the presence of nonguarding females causes a decrease in the survivorship of unguarded eggs. The proportion of eggs intact in unguarded egg masses was $0.61 \pm 0.29(N=15)$ where no nonguarding females were present and $0.37 \pm 0.35$ where nonguarding females were present $(t=2.2, P<0.05)$. The proportion of eggs that were noncollapsed in guarded egg masses did not vary with the presence $(0.94 \pm$ $0.07 ; N=4)$ or absence $(0.94 \pm 0.09 ; N=5)$ of nonguarding females $(t=$ $0.0, P>0.50)$.

\section{Cannibalism and Female Fecundity}

Among individual females on leaf clusters in nylon bags that cannibalized at least one egg, number of eggs cannibalized was positively correlated with female fecundity for viviparous females (product-moment correlation, $r=0.85$, $N=6, P<0.05)$ but not for oviparous females $(r=0.32, N=9, P>0.05)$. If these correlations are computed including females that cannibalized no eggs, the relationship remains significant for viviparous females $(r=0.76, N=16$, $P<0.01)$ and nonsignificant for oviparous females $(r=0.01, N=25, P>$ $0.05)$. The increase in viviparous female fecundity with number of eggs cannibalized was apparently not caused by a correlation between female size and number of eggs cannibalized $(r=0.01, P>0.05, N=9$ viviparous females that were measured).

\section{Causes of Variation in Female Reproductive Success}

The reproductive success of oviparous females in spring was considered to comprise four fitness components: fecundity (total number of eggs laid), egg survivorship, survivorship of larvae to adulthood, and adult body size of offspring.

Oviparous females laid an average of $39.5 \pm 8.7 \mathrm{eggs}$ in $1985(N=127$ complete clutches), $46.6 \pm 9.4$ eggs in $1986(N=121)$, and $44.9 \pm 9.9$ eggs in $1987(N=145)$. Oviparous female fecundity was highly correlated with body size in 1985 (product-moment correlation, $r=0.45, N=127, P<$ $0.001), 1986(r=0.42, N=121, P<0.001)$, and $1987(r=0.43, N=145$, $P<0.001)$. Female fecundity was also correlated with the density of fungal fruiting bodies on the leaves $(r=0.18, N=136, P<0.05)$. A multiple regression of female fecundity on female size and local fungus density gave a highly significant $R^{2}$ of 0.26 . Female size and fungus density were uncorrelated 
( $r=-0.01, N=137, P>0.50)$ and are assumed to affect female fecundity independently.

An average of $0.80 \pm 0.18$ of eggs in completed clutches were intact in $1985(N=108), 0.86 \pm 0.13$ were intact in $1986(N=121)$, and $0.86 \pm 0.15$ were intact in $1987(N=141)$. The proportion of eggs collapsed was uncorrelated with the total number of eggs in 1985 (product-moment correlation, $r$ $=-0.01, N=108, P>0.50), 1986(r=0.03, N=121, P>0.50)$, and $1987(r=-0.08, N=141, P>0.05$ ). The proportion of eggs collapsed was also uncorrelated with female size in $1985(r=0.07, N=108, P>0.05)$, $1986(r=-0.11, N=121, P>0.05)$, and $1987(r=0.01, N=141, P>$ 0.05 ). This independence of female size and egg survivorship may arise because females of different sizes lay eggs over about the same period of time, such that the eggs of all females are vulnerable for about the same period.

Among leaf clusters, average egg survivorship in completed clutches was negatively correlated with adult female density in 1986 (product-moment correlation, $r=-0.41, N=63, P<0.001)$ and $1987(r=-0.40, N=70, P$ $<0.001$ ). Moreover, in 1986 and 1987, a much lower proportion of eggs was collapsed where females were alone on a leaf cluster $(1986-0.08 \pm 0.08, N$ $=21 ; 1987-0.09 \pm 0.08, N=23$ ) than where more than one female was present $(1986-0.16 \pm 0.12, N=45 ; 1987-0.16 \pm 0.10, N=46 ; 1986-t$ $=2.6, P<0.05 ; 1987-t=2.8, P<0.01)$. The correlation between adult female density and egg survivorship remained significant when clusters with a single oviparous female were excluded (1986- $r=0.33, N=41, P<0.05$; $1987-r=0.49, N=45, P<0.01$ ). The reproductive mode (viviparous or oviparous) of females on a leaf cluster had no apparent effect on proportion of eggs collapsed, which did not vary between clusters with at least one viviparous female $(1986-0.16 \pm 0.14, N=14 ; 1987-0.16 \pm 0.09, N=24)$ and without viviparous females $(1986-0.16 \pm 0.10, N=16 ; 1987-0.15 \pm 0.12, N=$ $22 ; t<0.20, P>0.50$, in both years).

Among leaf clusters, the estimated average survivorship of female offspring from the egg stage to the pupal stage was $0.49 \pm 0.22$ in $1984(N=108)$ and $0.46 \pm 0.19$ in $1985(N=121)$. Female offspring survivorship was uncorrelated with both fungus density (product-moment correlation, $r=-0.11, N=$ $106, P>0.05$, data from 1984) and the density of eggs present on leaf clusters $(1984-r=-0.08, N=107, P>0.05 ; 1985-r=-0.23, N=65, P>$ $0.05)$.

The adult body size of female offspring was positively correlated with fungus density (product-moment correlation, $r=0.43, P<0.001, N=126$ leaf clusters, data from 1984). The correlation between female offspring survivorship and female offspring adult body size bordered on significance $(r=-0.19$, $N=99,0.10<P<0.05$, data from 1984). 


\section{DISCUSSION}

The observations, collections, and experiments indicate that egg cannibalism by adult females is an important selective pressure favoring maternal care in Elaphrothrips tuberculatus. This hypothesis is supported by the data showing that (1) females (but not males) readily cannibalize eggs in the laboratory and field, (2) experimental removal of guarding females in the field greatly decreases egg survivorship, (3) this decrease in egg survivorship was larger when nonguarding females were present locally, and (4) in field collections, adult female density was negatively correlated with egg survivorship, and the eggs of females that were alone on a leaf cluster had higher survivorship than the eggs of females in groups. Fox (1975) and Polis (1984) noted that cannibalism usually involves adult females eating immatures under conditions of high density, and the correlates of cannibalism discovered here for $E$. tuberculatus agree closely with these findings. Cannibalism has also been implicated in the evolution of maternal care in a staphylinid beetle (Ashe, 1987), and in the egg-guarding behavior of some primitively eusocial wasps (West-Eberhard, 1981).

Factors other than egg cannibalism that may select for female guarding behavior include parasitoid wasps, which attempt to oviposit into first-instar larvae while the larvae are on or near guarded egg masses, and unknown generalist predators, which may have caused the disappearance of all or part of some undefended egg masses in the experiments involving removal of guarding females. In addition, the finding that some eggs were collapsed when females were alone on a leaf cluster suggests that (1) other factors besides cannibalism sometimes cause collapse of eggs, (2) other females were present on these leaf clusters earlier in the breeding period, or (3) females occasionally cannibalize some of their own eggs. The relative importance of cannibalism, parasitoid wasps, and other factors for egg defense is unknown. However, the finding that guarding females normally abandon their egg masses prior to or soon after all of the eggs have hatched suggests that defense against wasps is relatively unimportant. Moreover, the lack of observation of any generalist egg predators on the leaves over the entire breeding period suggests that such predators are uncommon.

Whereas experimental removals of guarding females and observations indicate that the presence of the guarding female increases egg survivorship, the correlations of the number of prods until clutch abandonment (a measure of willingness to invest in the clutch) with total egg number, number of eggs intact, and proportion of the clutch laid (three measures of the value of the clutch) indicate that natural selection has adjusted guarding intensity to the costs and benefits of continued care versus abandonment during the guarding period. Similar relationships between the value of a brood to parents and the intensity of 
brood defense have been found in birds (Lemmetyinen, 1971; Barash, 1975; Robertson and Biermann, 1979; Grieg-Smith, 1980; Patterson et al., 1980; reviewed by Montgomerie and Weatherhead, 1988), fish (Coleman et al., 1985; Ukegbu and Huntingford, 1988), and a hemipteran bug (Tallamy, 1982). In $E$. tuberculatus, the proximate cue used by guarding females to adjust the intensity of defense could be investigated further by experimental removal or addition of eggs to guarded egg masses, followed by measuring the number of prods until abandonment.

The presence and intensity of maternal defense influence offspring survivorship into the first-instar stage. However, in E. tuberculatus, female reproductive success depends also on fecundity, local ecological and social factors affecting the success of egg-guarding, offspring survivorship to the adult stage, and size of offspring as adults. Data on the causes of variation in these fitness components shows that (1) female fecundity increases with body size and fungus density, (2) egg survivorship decreases with local density of adult females, and (3) offspring size as adults increases with fungus density.

What are the implications of these data for the selective pressures responsible for social behavior in thrips and other insects? In E. tuberculatus, as in some species of primitively eusocial insects (e.g., Batra, 1964; Gerret, 1964; West-Eberhard, 1981; Bourke, 1988), egg cannibalism by females appears to be an important cause of variation in reproductive success. However, whereas cannibalism in eusocial insects has apparently evolved in the context of social competition among kin and high investment in individual offspring, cannibalism in $E$. tuberculatus is probably a simple matter of utilizing a convenient nutritious food resource. The correlation between number of eggs cannibalized and fecundity for viviparous females suggests that cannibalism may increase female fitness; however, the reason for the lack of a fecundity effect for oviparous female $E$. tuberculatus is unknown.

Although E. tuberculatus is a haplodiploid species with maternal care, and offspring may sometimes develop in groups of all females related genetically by $3 / 4$ (as a result of single-sex broods and male mate-guarding), more advanced social interactions may not have evolved in this species for two primary reasons. First, the causes of variation in individual female reproductive success, which include such factors as female size, local food density, and local adult density, are not the type of factors that are influenced easily by social cooperation. Thus, female $E$. tuberculatus living in circumstances where their reproductive success would otherwise by relatively low could probably not gain by following any alternative subordinate or cooperative reproductive tactic. Second, helping behavior in thrips would probably be limited to brood defense, because thrips such as $E$. tuberculatus do not create and maintain a valuable habitat for rearing offspring such as a nest (gall-forming thrips are the lone exception). Moreover, cooperative brood defense would likely be found only among related adults, and $E$. tuberculatus adults normally spend only one generation in a patch before 
dispersing widely. The roles of habitat type, helping opportunities, and relatedness in thrips social biology could be investigated further through comparative studies, particularly among gall-forming and colonial under-bark species in which interacting adults are closely related. Such studies may help in determining the relative importance of relatedness and ecological factors in the evolution of sociality.

\section{ACKNOWLEDGMENTS}

I thank L. Vawter and L. Whittingham for helpful comments and discussions and M. F. O'Brien for identifying the eulophid wasp. This work was supported by an E. S. George Reserve Fellowship, and I am grateful to R. Nussbaum for allowing me to work at the George Reserve. Voucher specimens of Elaphrothrips tuberculatus have been deposited in the University of Michigan Museum of Zoology Insect Collection.

\section{REFERENCES}

Alexander, R. D., Noonan, K., and Crespi, B. J. (1989). The evolution of eusociality. In Sherman, P. W., Jarvis, J., and Alexander, R. D. (eds.), The Natural History and Social Behavior of Naked Mole Rats (in press).

Ananthakrishnan, T. N. (1984). Bioecology of Thrips, Indira, Oak Park, Mich.

Andersson, M. (1984). The evolution of eusociality. Annu. Rev. Ecol. Syst. 15: 165-189.

Ashe, J. S. (1987). Egg chamber production, egg protection, and clutch size among fungivorous beetles of the genus Eumicrota (Coleoptera: Staphylinidae) and their evolutionary significance. Zool. J. Linn. Soc. 90: 255-273.

Bagnall, R. S. (1915). On a collection of Thysanoptera from the West Indies with descriptions of new genera and species. Zool. J. Linn. Soc. 32: 495-507.

Barash, D. P. (1975). Evolutionary aspects of parental behavior: Distraction behavior of the alpine accentor. Wilson Bull. 87: 367-373.

Batra, S. W. T. (1964). Behavior of the social bee Lasioglossum zephyrum within the nest (Hymenoptera; Halictidae). Insectes Soc. 11: 159-185.

Bourke, A. (1988). Worker reproduction in the higher eusocial Hymenoptera. Q. Rev. Biol. 63: 291-311.

Coleman, R. M., Gross, M. R., and Sargent, R. C. (1985). Parental investment decision rules: A test in bluegill sunfish. Behav. Ecol. Sociobiol. 18: 59-66.

Crespi, B. J. (1986a). Territoriality and fighting in a colonial thrips, Hoplothrips pedicularius, and sexual dimorphism in Thysanoptera. Ecol. Entomol. 11: 119-130.

Crespi, B. J. (1986b). Size assessment and alternative fighting tactics in Elaphrothrips tuberculatus (Insecta: Thysanoptera). Anim. Behav. 34: 1324-1335.

Crespi, B. J. (1987). Behavioral Ecology of Mycophagous Thysanoptera, Ph.D. dissertation, University of Michigan, Ann Arbor.

Crespi, B. J. (1988a). Risks and benefits of lethal male fighting in the colonial, polygynous thrips Hoplothrips karnyi (Insecta: Thysanoptera). Behav. Ecol. Sociobiol. 22: 293-301.

Crespi, B. J. (1988b). Sex ratio selection in a bivoltine thrips. I. Conditional sex ratio manipulation and fitness variation. Evolution 42: 1199-1211.

Crespi, B. J. (1988c). Alternative male mating tactics in a thrips: Effects of sex ratio variation and body size. Am. Midl. Nat. 119: 83-92.

Crespi, B. J. (1989). Facultative viviparity in a thrips. Nature 337: 357-358.

Edgerly, J. S. (1987). Maternal behavior of a webspinner (order Embiidina). Ecol. Entomol. 12: $1-11$. 
Eickwort, G. C. (1981). Presocial insects. In Hermann, H. R. (ed.), Social Insects, Vol. 2, Academic Press, New York, pp. 199-280.

Fox, L. R. (1975). Cannibalism in natural populations. Annu. Rev. Ecol. Syst. 6: 87-106.

Geret, G. (1964). Le comportement d'oophagie differentielle chez Polistes gallicus L. (Hymenoptera, Vespidae). Insectes Soc. 11: 343-382.

Grieg-Smith, P. W. (1980). Parental investment in nest defense by stonechats (Saxicola torquata). Anim. Behav. 28: 604-619.

Haga, K. (1980). The life-history of Bactridothrips brevitubus (Takahashi) (Idolothripinae). XVI International Congress of Entomology, Kyoto, "Conference of Thysanopterists," pp. 1-8.

Hamilton, W. D. (1964). The genetical evolution of social behavior. I, II. J. Theor. Biol. 7: $1-52$.

Hamilton, W. D. (1972). Altruism and related phenomena, mainly in social insects. Annu. Rev. Ecol. Syst. 3: 193-232.

Hean, A. F. (1943). Notes on maternal care in thrips. J. Entomol. Soc. So. Afr. 6: 81-83.

Kiester, A. R., and Strates, E. (1984). Social behavior in a thrips from Panama. J. Nat. Hist. 18: 303-314.

Lemmetyinen, R. (1971). Nest defense behavior of common and arctic terns and its effects on the success achieved by predators. Ornis Fenn. 48: 13-24.

Lin, N. (1964). Increased parasite pressure as a major factor in the evolution of social behavior in halictine bees. Insectes Soc. 11: 187-192.

Litte, M. (1977). Aspects of the social biology of the bee Halictus ligatus in New York State (Hymenoptera, Halictidae). Insectes Soc. 24: 9-36.

Mani, M. S., and Rao, S. N. (1950). A remarkable case of maternal solicitude in a thrips from India. Curr. Sci. 19: 217.

Michener, C. D. (1974). The Social Behavior of the Bees, Harvard University Press, Cambridge, Mass.

Montgomerie, R. D., and Weatherhead, P. J. (1988). Risks and rewards of nest defense by parent birds. Q. Rev. Biol. 63: 167-187.

Patterson, T. L., Petrinovich, L., and James, D. K. (1980), Reproductive value and appropriateness of responses to predators by white-crowned sparrows. Behav. Ecol. Sociobiol. 7: 227231.

Polis, G. A. (1984). Intraspecific predation and "infant killing" among invertebrates. In Hausfater, G., and Hrdy, S. B. (eds.), Infanticide: Comparative and Evolutionary Perspectives, Aldine Press, New York, pp. 87-104.

Ramakrishna Ayyar, T. V. (1928). A contribution to our knowledge of the Thysanoptera of India. Memoirs Dept. Agr. Entomol. Ser. 10: 217-316.

Robertson, R. J., and Biermann, G. C. (1979). Parental investment strategies determined by expected benefits. Z. Tierpsychol. 50: 124-128.

Stannard, L. J. (1968). The thrips, or Thysanoptera of Illinois. Ill. Nat. Hist. Surv. Bull. 29: $1-552$.

Tallamy, D. W. (1982). Age-specific matemal defense in Gargaphia solani (Hemiptera: Tingidae). Behav. Ecol. Sociobiol. 11: 7-11.

Tallamy, D. W., and Wood, T. K. (1986). Convergence patterns in subsocial insects. Annu. Rev. Entomol. 31: 369-390.

Ukegbu, A. A., and Huntingford, F. A. (1988). Brood value and life expectancy as determinants of parental investment in male three-spined sticklebacks Gasterosteus aculeatus. Ethology 78: $72-82$.

West-Eberhard, M. J. (1978). Polygyny and the evolution of social behavior in wasps. J. Kans. Entomol. Soc. 51: 832-856.

West-Eberhard, M. J. (1981). Intragroup selection and the evolution of insect societies. In Alexander, R. D., and Tinkle, D. W. (eds.), Natural Selection and Social Behavior, Chiron Press, New York, pp. 3-17. 